\title{
Association between Confidence in Smiling and Esthetic Characteristics: A Cross-sectional Study in Chengalpattu
}

\author{
Prabhu Subramani ${ }^{1}$, Srividya Neelakantan ${ }^{2}$, Sheran Priyadarshini Johnson ${ }^{3}$, Srilatha Srinivasan ${ }^{4}$
}

\begin{abstract}
Background: A multitude of parameters influences the smile of a person. Individuals with pleasant smiles are often construed to be easily approachable.

Aim and objective: This study aims to analyze the dental, facial, and gingival characteristics associated with confidence in smiling in the general population of Chengalpattu.

Materials and methods: A cross-sectional questionnaire study was conducted in the general population among individuals from 18 to 50 years of age $(N=175)$ after required history elicitation and clinical examination. Independent samples $t$-test was used to analyze the self-perception about the beauty of teeth across gender.

Results: A positive correlation between dental health status and confidence in smiling was found $(p<0.05)$. There was no significant association in the perception of study subjects regarding the beauty of teeth and liking toward their own smile across gender $(p>0.05)$. The parameters that were chosen the most by the individuals who wished to have a better smile were the alignment of teeth $(n=43,16.6 \%)$ followed by teeth shape $(n=35,13.5 \%)$ and teeth color $(n=32,12.4 \%)$.

Conclusion: Self-perception of the smile has an impact on the psychosocial well-being of the individual as well as confidence during smiling. Clinical significance: Understanding the perception of the general population about dentofacial features and their effect on an individual's confidence is of paramount importance for dental practitioners to provide better esthetic and functional results.

Keywords: Confidence, Esthetics, Self-perception, Smile.

Journal of Scientific Dentistry (2021): 10.5005/jp-journals-10083-0941
\end{abstract}

\section{INTRODUCTION}

A smile is a distinguished facial expression formed by flexing the perioral muscles. ${ }^{1}$ People with smiling faces are often interpreted as more sociable than people with neutral faces. An esthetically pleasing smile positively impacts an individual's confidence. ${ }^{2}$ Smile has two dimensions to it: objective as well as subjective. ${ }^{3}$ Subjectivity is based on the individual's perception, whereas objectivity is based on the intrinsic features and characteristics of perioral and intraoral tissues. The number of individuals approaching dentists with the primary aim of smile correction is exponentially increasing. Dental esthetic imperfections that encourage patients to seek treatment can broadly be categorized as dental, facial, and gingival anomalies. ${ }^{4}$ This study aims at analyzing the association between confidence in smiling and esthetic characteristics.

\section{Materials and Methods}

\section{Sample Selection and Size Calculation}

This is a cross-sectional study was conducted in the general population of Chengalpattu. The sample size was calculated using OpenEpi (version 3.01) $(n=80)$ based on the study conducted by Muniz et al. ${ }^{4}$

\section{Inclusion Criteria}

The general population in Chengalpattu from 18 to 50 years of age in both genders with sound oral health.

\section{Exclusion Criteria}

Individuals who have undergone orthodontic treatment, restorative/prosthetic rehabilitation in the maxillary, and
${ }^{1-4}$ Department of Public Health Dentistry, Asan Memorial Dental College and Hospital, Chengalpattu, Tamil Nadu, India

Corresponding Author: Prabhu Subramani, Department of Public Health Dentistry, Asan Memorial Dental College and Hospital, Chengalpattu, Tamil Nadu, India, Phone: +91 9080756119, e-mail: prabhu.dent@gmail.com

How to cite this article: Subramani P, Neelakantan S, Johnson SP, Srinivasan S. Association between Confidence in Smiling and Esthetic Characteristics: A Cross-sectional Study in Chengalpattu. J Sci Dent 2021;11(1):16-18.

Source of support: Nil

Conflict of interest: None

mandibular anterior teeth region were excluded. Subjects with signs of chronic periodontal disease and caries in the anterior teeth region were also excluded.

\section{Ethical Aspects}

This study was approved by the Institutional Scientific Research Committee of Asan Memorial Dental College and Hospital, and consent was obtained from all the participants for data collection.

\section{Clinical Procedure}

The questionnaire was issued for 175 participants. The procedure was explained and subsequently, data were collected from the participants by the researchers. 


\section{Questionnaire}

The questionnaire used here comprised 6 close-ended questions to assess the self-perception and confidence during smiling. Four of these questions had yes/no choices.

- Have you ever judged your own smile?

- Has your dentist ever assessed your smile?

- Do you feel confident while smiling?

- While coming across people with better smiles, have you ever desired to have a similar one?

In addition to these, a question on what do they wish to change in their smile was included and multiple options such as lips, gums exposure, gum color, teeth size, color, shape, arrangement, the gap between teeth, others, and none were given. Additionally, the study subjects were asked to rate the importance of esthetics in their life as well their smile from 0 to 10 for assessing self-perception numerically.

\section{Statistical Analysis}

Was performed using the SPSS version 23.

\section{Results}

Among the $N=175$ study subjects, $n=85$ (48.6\%) were male and $n=90$ (51.4\%) were female. Table 1 depicts the confidence in smiling in the study population; $80 \%(n=140)$ of the participants stated that they felt confident while smiling and $20 \%(n=35)$ nonconfident. Out of 175, 105 (60\%) individuals wished to have a better smile when they came across people with one. Table 2 shows the self-perception of esthetic characteristics associated with smiling. It was found that $n=69(26.6 \%)$ wished not to change any of their

Table 1: Perception about smile in the study population

\begin{tabular}{lllc}
\hline S.no. & Question & Yes n (\%) & No n (\%) \\
\hline 1 & $\begin{array}{l}\text { Have you ever judged your own } \\
\text { smile? }\end{array}$ & $122(69.7)$ & $53(30.3)$ \\
2 & $\begin{array}{l}\text { Has your dentist ever assessed } \\
\text { your smile? }\end{array}$ & $29(16.6)$ & $146(83.4)$ \\
3 & $\begin{array}{l}\text { Do you feel confident while } \\
\text { smiling? }\end{array}$ & $140(80)$ & $35(20)$ \\
4 & $\begin{array}{l}\text { While coming across people with } \\
\text { better smiles, have you desired } \\
\text { to have a similar one? }\end{array}$ & $705(60)$ & $70(40)$ \\
& & & \\
\hline
\end{tabular}

dentofacial features. The parameters that were most chosen by the participants who wished to have a better smile were the alignment of teeth ( $n=43,16.6 \%$ ) followed by the shape of teeth ( $n=35$, $13.5 \%)$ and teeth color ( $n=32,12.4 \%)$. No significant association in the perception of study subjects regarding the beauty of their teeth and liking toward their own smile across gender was found using the independent samples $t$-test (Table 3). Table 4 presents the correlation between confidence in smiling and dental health status of the study subjects and shows that there is a significant positive correlation between the dental health status and confidence in smile among the study population.

\section{Discussion}

The cross-sectional study was conducted to determine the association between confidence in smiling and esthetic characteristics in the general population. Facial expressions and dental esthetics play a vital role in societal interactions. Individuals seeking dental treatment for smile correction are motivated by the demand for esthetics. Though esthetics has subjective and objective facets, dental practitioners must understand the perception of the general population. In smile designing, the fundamental goal is to create a natural, pleasing, harmonious appearance.

In this study, $n=122$ (69.7\%) stated that they have evaluated their smile compared to $89.18 \%$ in a study conducted in the Brazilian population. ${ }^{4}$ Our study was conducted in a mixed population whereas the latter was in an urban population. Thus, this depicts that the nature of the population influences the perception of the smile.

Upper lip length and curvature, lip elevation, lip width, symmetry, and fullness impact the attractiveness of a smile. ${ }^{5}$ In this study, $n=20$ (7.7\%) participants wished to change their lip features, whereas $11.2 \%$ preferred in a study conducted among young adults in Aligarh. ${ }^{6}$ This suggests that older individuals are satisfied with their esthetic aspects compared to younger individuals. Gingival exposure, color, zenith, and papillary contours have the potential to adversely affect the smile. ${ }^{1,7}$ In our study, $n=15(5.8 \%)$ preferred to change their gingival display and color. Earlier studies have reported that smiles with the excessive gingival display were rated to be less attractive by the general population consequently resulting in a lack of confidence while smiling. ${ }^{8}$

The dental parameters affecting the perception of a smile include teeth size, shape, color, and alignment. In some individuals, dental discrepancies may not be pronounced due to the equilibrium

Table 2: Self-perception on esthetic characteristics in the study population

\begin{tabular}{|c|c|c|c|c|c|}
\hline S. no. & Factor & $N(\%)$ & S. no. & Factor & $N(\%)$ \\
\hline 1 & Lips & $20(7.7)$ & 6 & Shape of teeth & $35(13.5)$ \\
\hline 2 & Gums Visibility & $3(1.2)$ & 7 & Alignment of teeth & $43(16.6)$ \\
\hline 3 & Gums color & $12(4.6)$ & 8 & Spacing between teeth & $25(9.7)$ \\
\hline 4 & Size of teeth & $20(7.7)$ & 9 & Others & Nil \\
\hline 5 & Teeth color & $32(12.4)$ & 10 & None & 69 (26.6) \\
\hline
\end{tabular}

Table 3: Perception of study subjects regarding the beauty of their teeth and liking toward their own smile across gender

\begin{tabular}{llllll}
\hline S. no. & Question* & Male* Mean $\pm S D$ & Female* Mean $\pm S D^{*}$ & $t$ value & $p$ value \\
\hline 1 & Do you think esthetics is important in your life? & $8.51 \pm 1.72$ & $8.63 \pm 1.78$ & 0.47 & 0.66 \\
2 & Do you like your smile? & $7.76 \pm 2.10$ & $8.0 \pm 1.81$ & 0.22 & 0.40 \\
\hline
\end{tabular}

*Independent samples $t$-test, $(p>0.05$ —not significant) 
Table 4: Correlation between confidence in the smile and dental health status

\begin{tabular}{lllll}
\hline Dental health status & Confidence in smile & $t$ value & $R$-value & $p$ value \\
\hline Satisfied & $8.14 \pm 1.85$ & 3.06 & +0.227 & 0.003 \\
Not-satisfied & $7.11 \pm 2.07$ & & & \\
\hline
\end{tabular}

*Pearson's correlation $(p<0.05$-statistically significant)

between their dental and facial features. $n=20(7.7 \%)$ individuals wished to alter their teeth size in our study which is in accordance with the findings of a study conducted among undergraduates to assess self-perception of the smile in Nigeria where $4.8 \%$ chose teeth size. ${ }^{9}$ This depicts that teeth size is also one of the crucial factors determining smile attractiveness.

Generally, laymen believe "white teeth" to be "ideal teeth color". In our study, $n=32$ (12.4\%), were unsatisfied with their teeth color whereas a study carried out in Malaysia showed $56.2 \%$ were not satisfied with their teeth color. ${ }^{10}$ This suggests that perception toward dentofacial appearance is influenced by the nativity, ethnicity as well as geographic distribution of the study population. A study conducted to assess the influence of tooth color on social perception concluded that "whitened teeth" were related to a high degree of attractiveness thus consequently boosting one's self-confidence. ${ }^{11}$

Atypical tooth forms affect the gingival esthetic line (GAL) which in turn prompts an unappealing smile and consequently low confidence while smiling. ${ }^{12}$ Rather than as a separate entity, it is the relative balance between dentition and the facial tissues that exerts an influence on esthetics. Numerous studies to figure out the association between face form and morphology of maxillary central incisors have been carried out in the literature. ${ }^{13,14}$

Alignment of teeth was the most chosen factor in this study $(n=43)$. This is in agreement with the findings from a study conducted in a population from three different countries in which the Japanese chose alignment of teeth the most but not Americans who chose teeth color. ${ }^{15}$ This depicts that cultural and anthropological factors influence the perception of attractiveness.

It is often presumed that females are inclined toward esthetics to a greater extent when compared to males. In this study, the perception toward the beauty of teeth as well as liking toward their own smile across gender showed no significance $(p>0.05)$ which is not in agreement with earlier studies where females were significantly dissatisfied with their smiles. ${ }^{10}$ In contrast, a study conducted in Israel concluded that women were satisfied considerably with their dental appearance in comparison with men. ${ }^{16}$ These findings suggest that further investigations are required to determine the association between gender and smile perception. From the above-said discussion, it can be seen that a wide array of dental, facial, and gingival features contribute to a pleasant smile as well as improved confidence during smiling.

\section{Conclusion}

A plethora of parameters influences an individual's smile as well as confidence in smiling. The dental practitioner, bearing in mind the patient's self-perception and degree of confidence, should try to achieve a striking balance between the dental, facial, and gingival tissues both functionally and esthetically.

\section{Clinical Significance}

Understanding the self-perception of study subjects as well as following basic principles in smile designing/correction is essential.

\section{Acknowledgment}

The authors would like to express their gratitude to the Department of Public Health Dentistry, Asan Memorial Dental College and Hospital, Chengalpattu, Tamil Nadu, India.

\section{References}

1. Manjula WS, Sukumar MR, Kishorekumar S, Gnanashanmugam K, Mahalakshmi K. Smile: a review. J Pharm Bioallied Sci 2015;7(Suppl 1):S271-S275. DOI: 10.4103/0975-7406.155951.

2. Armalaite J, Jarutiene M, Vasiliauskas A, et al. Smile aesthetics as perceived by dental students: a cross-sectional study. BMC Oral Health 2018;18(1):225. DOI: 10.1186/s12903-018-0673-5.

3. Sriphadungporn C, Chamnannidiadha N. Perception of smile esthetics by laypeople of different ages. Prog Orthod 2017;18(1):8. DOI: 10.1186/ s40510-017-0162-4.

4. Muniz FWMG, Cavalcante DJ, Moreira MMSM, Rodrigues LKA, de Oliveira Fernandes CA, de Almeida, PC, et al. Association between confidence in smiling and esthetic characteristics. J Esthet Restor Dent 2017;29(2):E56-E66. DOI: 10.1111/jerd.12278.

5. Sabri R. The eight components of a balanced smile. J Clin Orthod: JCO 2005;39(3):155-167 Davis NC. Smile design. Dent Clin North Am 2007;51(2):299-318, vii.

6. Afroz S, Rathi S, Rajput G, Rahman SA. Dental esthetics and its impact on psycho-social well-being and dental self-confidence: a campus based survey of north Indian university students. J Indian Prosthodont Soc 2013;13(4):455-460. DOI: 10.1007/s13191-012-0247-1.

7. Bhuvaneswaran M. Principles of smile design. J Conserv Dent 2010;13(4):225-232. DOI: 10.4103/0972-0707.73387.

8. Geron S, Atalia W. Influence of sex on the perception of oral and smile esthetics with different gingival display and incisal plane inclination. Angle Orthod 2005;75(5):778-784. DOI: 10.1043/0003-3219(2005)75[778:IOSOTP]2.0.CO;2.

9. Isiekwe I, Aikins E. Self-perception of dental appearance and aesthetics in a student population. Int Orthod 2019;17(3):506-512. DOI: 10.1016/j.ortho.2019.06.010.

10. Tin-Oo MM, Saddki N, Hassan N. Factors influencing patient satisfaction with dental appearance and treatments they desire to improve aesthetics. BMC Oral Health 2011;11(1):6. DOI: 10.1186/14726831-11-6.

11. Kershaw S, Newton J, Williams D. The influence of tooth colour on the perceptions of personal characteristics among female dental patients: comparisons of unmodified, decayed and 'whitened' teeth. Br Dent J 2008;204(5):E9. DOI: 10.1038/bdj.2008.134.

12. Ahmad I. Anterior dental aesthetics: gingival perspective. Br Dent J 2005;199(4):195-202. DOI: 10.1038/sj.bdj.4812611.

13. Pedrosa VO, França FMG, Flório FM, Basting RT. Study of the morphodimensional relationship between the maxillary central incisors and the face. Brazilian Oral Res 2011;25(3):210-216. DOI: 10.1590/s180683242011005000010.

14. Mehndiratta A, Bembalagi M, Patil R. Evaluating the association of tooth form of maxillary central incisors with face shape using AutoCAD software: a descriptive study. J Prosthodont 2019;28(2):e469-e472. DOI: 10.1111/jopr.12707.

15. Funaki J, Funaki S, Zaitsu T, Noguchi BS, Nasution FH. International comparison of perceived smile attractiveness and consciousness. IJCPD 2020;16:209-214.

16. Samorodnitzky-Naveh GR, Geiger SB, Levin L. Patients' satisfaction with dental esthetics. J Am Dent Assoc 2007;138(6):805-808. DOI: 10.14219/jada.archive.2007.0269. 